\title{
MISCELLANEA
}

\section{The North of England Industrial Health Advisory Service}

BY

\section{R. C. BROWNE and D. GRIEVES}

In January 1960, the North of England Industrial Health Advisory Service was launched. It is sponsored jointly by the trade unions, management, and King's College, Newcastle upon Tyne, with support from both the Nuffield Foundation and the Nuffield Provincial Hospitals Trust.

This new service offers industry consulting facilities which are not already covered by the National Health Service, at a charge of $2 \mathrm{~s}$. per employee per annum, with an additional charge, at cost price, for any special investigations carried out. Every item of work is carefully costed. Advice is not withheld from non-member firms, but it is given on a cost-plus basis.

The subscription is low, but it is calculated on a working population of about one million in a very heavily industrialized area.

The University has agreed that its Department of Industrial Health may loan its professor, senior lecturer, and lecturer in occupational hygiene to the service, for the time being. During the first year's work, moreover, a house has also been provided.

There is a Committee of Management of six members, composed of equal numbers of University, industrial, and T.U.C. representatives.

On the clinical side, the service advises about the resettlement of cases of long-term sickness, and, on the scientific side, it advises on the whole range of occupational hygiene and environmental problems. It possesses a fully equipped occupational hygiene laboratory under the direction of the University lecturer in occupational hygiene.

The growth of the service is expected to be slow, but during the first year's work, 16 firms of varying size, covering a wide variety of processes, became members. These firms have a total manpower of 7,500 workpeople, ranging from a very small firm with 24 employees, to one employing as many as 1,841 . Although the very small firms have the greatest need of such a service, it has been found that they are the least likely to join. The most promising group seems to be that which employs between 100 and 500 workers.

A variety of interesting problems have already been dealt with for both member and non-member firms. These have included the investigation of a dust hazard in a cabinet-making factory, and a lead-in-air survey in a shipbreaking yard together with the urinary lead estimations of the men employed. A survey of the atmosphere of a department in an electrical engineering firm engaged in the manufacture of lead enamels, together with urinary lead estimations of the men employed, has also been made. The noise level has been estimated in the bottling department of a brewery, and a dust survey of the oil gasification plants in the North of England is in progress. A bulletin is issued by the service every six months.

The Committee of Management of this service have been eager to tailor it so as to provide, on a regional basis and at a price which firms in the North are prepared to pay, long-term sickness and occupational hygiene advice. Neither of these can be obtained from the National Health Service.

\section{General Assembly of the Permanent Commission and International Association on Industrial Health}

Two Sessions of the General Assembly were held in New York in July 1960, during the International Congress. The following information is extracted from the Minutes of these Sessions through the courtesy of the SecretaryGeneral, Professor Enrico Vigliani. Sixty-four members attended each session. President Forssman opened the meeting and welcomed the members present. At the previous Congress in Helsinki, four sub-committees were appointed to consider the following subjects (the name of the chairman of each sub-committee is given in brackets).

Absenteeism (Professor Forssman, Sweden).-The Report of the Sub-committee will be published in the Proceedings of the Conference. This Report deals with definitions, recommendations, and information to be given when planning studies on absenteeism in industry.

Maximum Allowable Concentrations of Toxic Substances (Professor Truhaut, France).-An international symposium was held in Prague in 1959 under the sponsorship of the Permanent Commission and of the International Union of Pure and Applied Chemistry. Organized by Professor Teisinger, the particular aim of the symposium was to discuss the reasons for the profound differences in recommended maximum allowable concentrations between the various countries, with special reference to the U.S.A. and U.S.S.R. The resolutions of this symposium will be published by the: International Union of Pure and Applied Chemistry. 
Occupational Health in the Textile Industry (Professor Schilling, United Kingdom).--Twenty-two countries had been asked to supply data on the incidence of byssinosis in their national textile industry. From the replies received it was concluded that byssinosis occurs in at least eight countries and probably more. In 1959 a meeting on byssinosis was held in London, sponsored by the Medical Research Council with international attendance. In 1960 an international meeting was held in Milan on the pathogenesis of byssinosis and related conditions. Further meetings on the pathogenesis and prevention of the disease will be held during the next three years.

Constitution of the Commission (Professor Vigliani, Italy).-A revised draft of the constitution has been prepared. This was discussed and, as a number of matters remained outstanding, it was decided that the subcommittee should continue its work and prepare a final draft Constitution for submission to the next General Assembly. It was agreed that the title of the organization be changed from "Permanent Committee" to "Permanent Commission" and that the Bureau should be authorized to nominate new members of the Permanent Commission during the period between international congresses.

After discussion it was agreed that there should be no official journal of the Permanent Commission, and that information should be circulated to all journals in the field of occupational health.

It was decided to accept the invitation of the Spanish Government to hold the next Congress in Madrid in 1963.

Professor Sven Forssman was re-elected President for the triennium 1960-63. Professor R. E. Lane was elected a Vice-President on the nomination of the British Members. Also elected Vice-Presidents were Professor E. W. Baader (Germany), L. Greenburg (U.S.A.), A. A. Letavet (U.S.S.R.), L. Noro (Finland), and J. Teisinger (Czechoslovakia). Professor Enrico Vigliani was reelected Secretary-General and elected Treasurer (Address: Clinica del Lavoro, Via S. Barnaba 8, Milan, Italy).

The British members of the Permanent Commission and International Association on Industrial Health are:Professor R. E. Lane (Vice-President of the Commission); Dr. L. G. Norman (Chairman, British Members); Professor R. S. F. Schilling (Hon. Secretary, British Members); Dr. A. T. Doig; Dr. N. Langdon Lloyd; Mrs. I. G. Doherty; Dr. Donald C. Norris; Dr. Sibyl Horner; Dr. E. R. A. Merewether; Dr. J. M. Davidson; Dr. A. I. G. McLaughlin; Dr. M. W. Goldblatt; Dr. Donald Hunter; Dr. A. Lloyd Potter; T. E. A. Stowell, Esq.; Dr. A. Meiklejohn; Sir Walter Chiesman.

\section{Two New Medical Centres}

\author{
H. J. Heinz Co. Ltd.
}

A large new factory at Kitt Green, near Wigan, Lancs., was opened in 1959.

The following particulars were provided by Dr. J. C. Graham, Chief Medical Officer. The medical department provides a personal service for any employee who suffers from illness or accident at work; it is also concerned with environmental working conditions, efficiency of operation, and a high quality of product.

The medical department is situated in the Employee Services Building at ground level, opening on to the main personnel corridor next to the south entrance. It has a floor space of 3,360 square feet. A plan of the accommodation is given in Fig. 1.

The lay-out of the department was dictated to some extent by the site allocated to the medical services. Ideally, the medical department should be situated as near to the centre of a factory as possible to curtail the distances to be covered by employees requiring treatment; at the same time, it is necessary for it to be conveniently situated for access by new employees attending for medical examination. The decision, however, to locate all employee services in the one building, precluded any possibility of it being in the centre of the factory. Sited as it is, however, adjacent to other service departments, it has its own entrance and is a self-contained unit; this is important to preserve the confidential doctor-patient relationship.

To reduce noise interference to a minimum the examination suite faces an internal courtyard, whereas the surgeries and dental unit face south to give maximum daylight. The treatment rooms have tiled walls and floors; the other rooms are finished in plaster. All ceilings are covered with acoustic tiles. The artificial lighting is mainly by fluorescent tubes fitted with plastic diffusers giving an illumination of at least 30 lumens per square foot in the working areas. The lay-out is related to four separate functions of occupational health services.

Treatment and Casualty Service.-The rest rooms, surgeries, sterilizing and minor treatment room are designed for the treatment of all personnel with minor or major conditions arising at work. The larger of the two rest rooms has double doors opening directly on to the main corridor and surgery to allow easy access for a stretcher trolley. The minor treatment room is also intended for use as a recovery room linked with the work in the dentist's surgery.

The waiting area has been purposely kept small. This room also contains a refrigerator so that patients on a milk diet may receive their treatment without interfering with the general flow of patients.

The main surgery area (Fig. 2) is divided by a curtain 


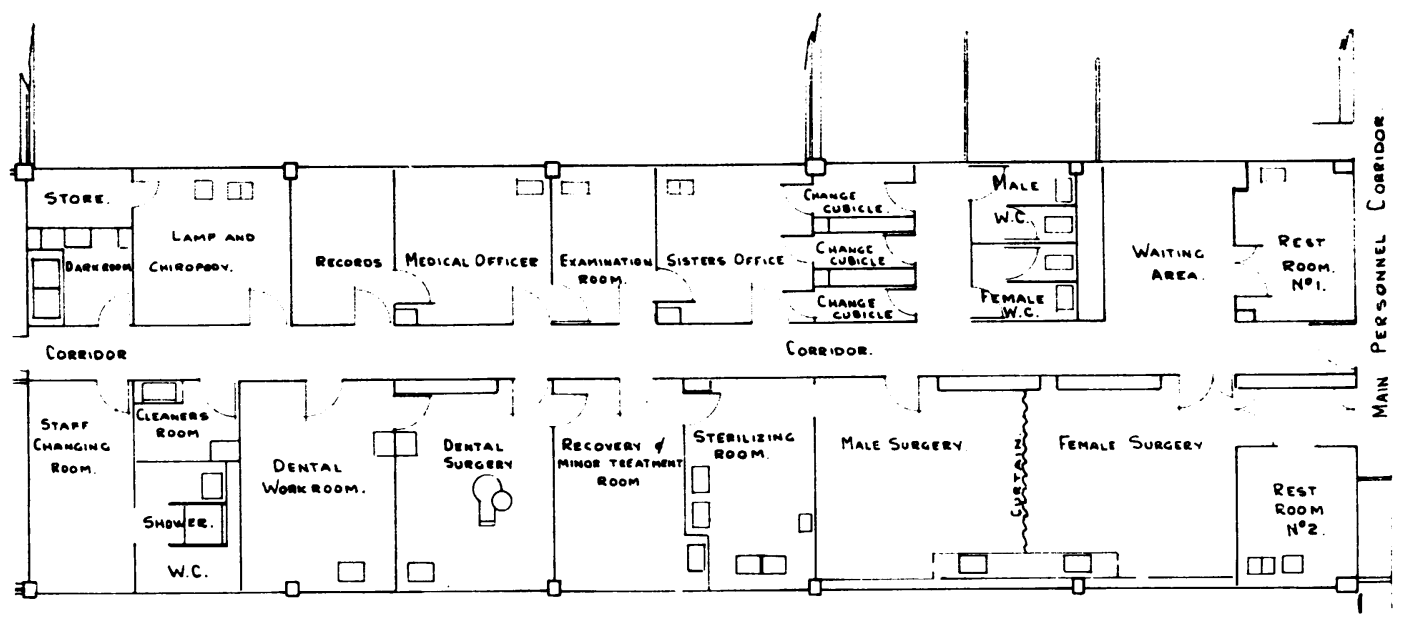

FIG. 1.-Kitt Green factory medical department. The department is approximately 100 feet in length and 34 feet in width.

separating the sexes, and a special area is set aside for the treatment of eye conditions; all eye treatments are given with the patient lying down.

Medical Examinations and Consultations.-The consulting suite is designed to allow a flow of personnel from the waiting area to the changing cubicles which, in turn, gives access to the sister's office where a trained sister can take the occupational and health histories and record the usual information before reference to the doctor who normally examines the patient in the examination room. The sister's office is also used for health counselling and for interviewing on return to work ail personnel who have been absent due to sickness.

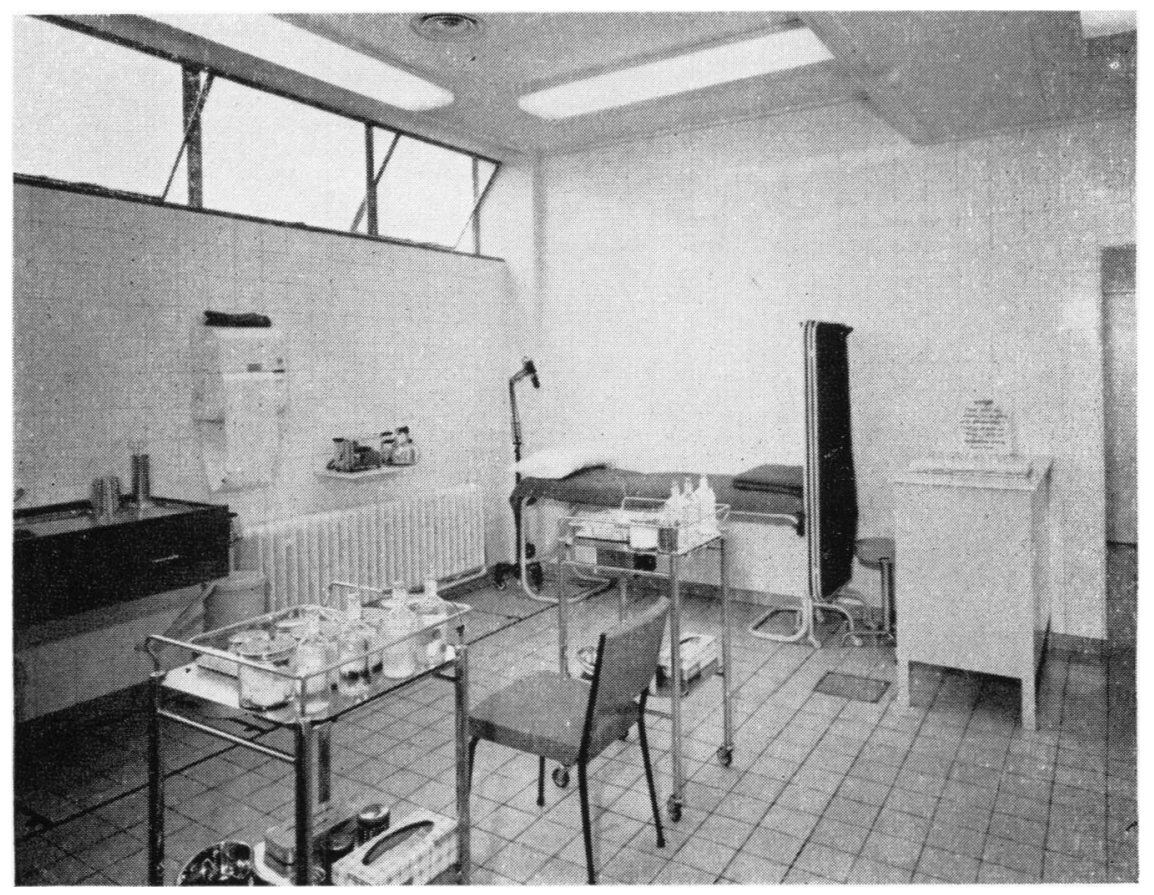

FIG. 2.-General view of surgery, Kitt Green. There is a separate sterilizing room. 
Ancillary Services.-The dental unit consists of a surgery, workroom, and a dark room, since it is intended to equip the dental surgery with an $x$-ray machine, and, as mentioned above, the dentist has part use of the minor treatment room as and when required.

Across the corridor is a multi-purpose room for use by the chiropodist whose services are provided free to all employees. Minor physiotherapy treatment can also be given at the request of an employee's general practitioner.

Administration.-The records office is adjacent to and gives access to the medical officer's room and contains records of all employees; sickness absence statistics are compiled from these records. The nursing staff are provided with a changing room with shower accommodation.

Staff.-It is ultimately intended to provide services for 3,000 personnel; at present there are 2,200 employees and a 24-hour service is provided five days per week. The full-time medical officer and sister-in-charge are also responsible for the medical department at another factory of the Company seven miles away which employs a further 1,600 persons. Additionally, there are two state registered nurses and three state enrolled assistant nurses to provide the 24-hour cover. The medical officer has a full-time secretary who is responsible for the sickness absence records. A cleaner is also employed.

\section{Richard Thomas and Baldwins Ltd.}

A new medical centre was opened at the Ebbw Vale Works in February 1961. The following description was provided by Dr. J. S. Spickett, Chief Medical Officer.

A plan of the new centre is given at Fig. 3. The centre provides most of the services normally found in a hospital out-patients' department.

The central area of the building provides space for a waiting room and a large records office and placed around this are the consulting rooms and treatment departments. Three full-time doctors are based at the works and each has his own consulting room, with a curtained-off cubicle.

For minor injuries there is a large dressings room, and in this there are cubicles for minor surgical procedures, treatment of eye injuries and privacy for carrying out more elaborate dressings (Fig. 4).

Behind this is an ambulance drive-in and a resuscitation ward, with three beds, where more serious cases can be dealt with. Next to it is the $x$-ray department, fitted with a modern unit that ensures that the patient receives the smallest possible $x$-ray exposure.

In the records room preliminary particulars of newcomers to the Company are recorded by the nursing staff before examination by the doctor, and medical records of all employees are housed.

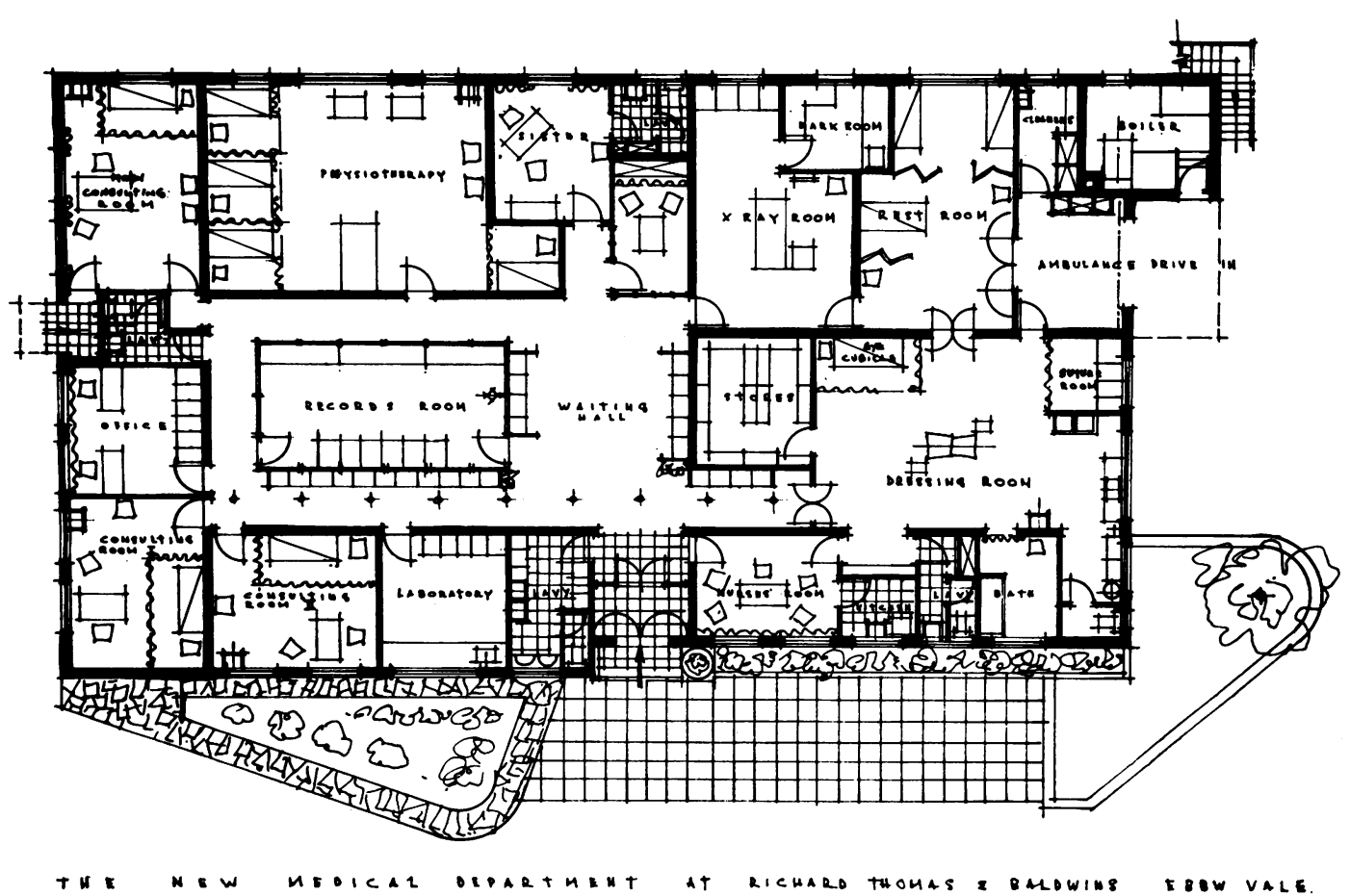

FIG. 3.-The new medical department at Richard Thomas and Baldwins, Ebbw Vale. The overall length of the front of the building is 102 feet, of the back 110 feet, and the width is 58 feet. 


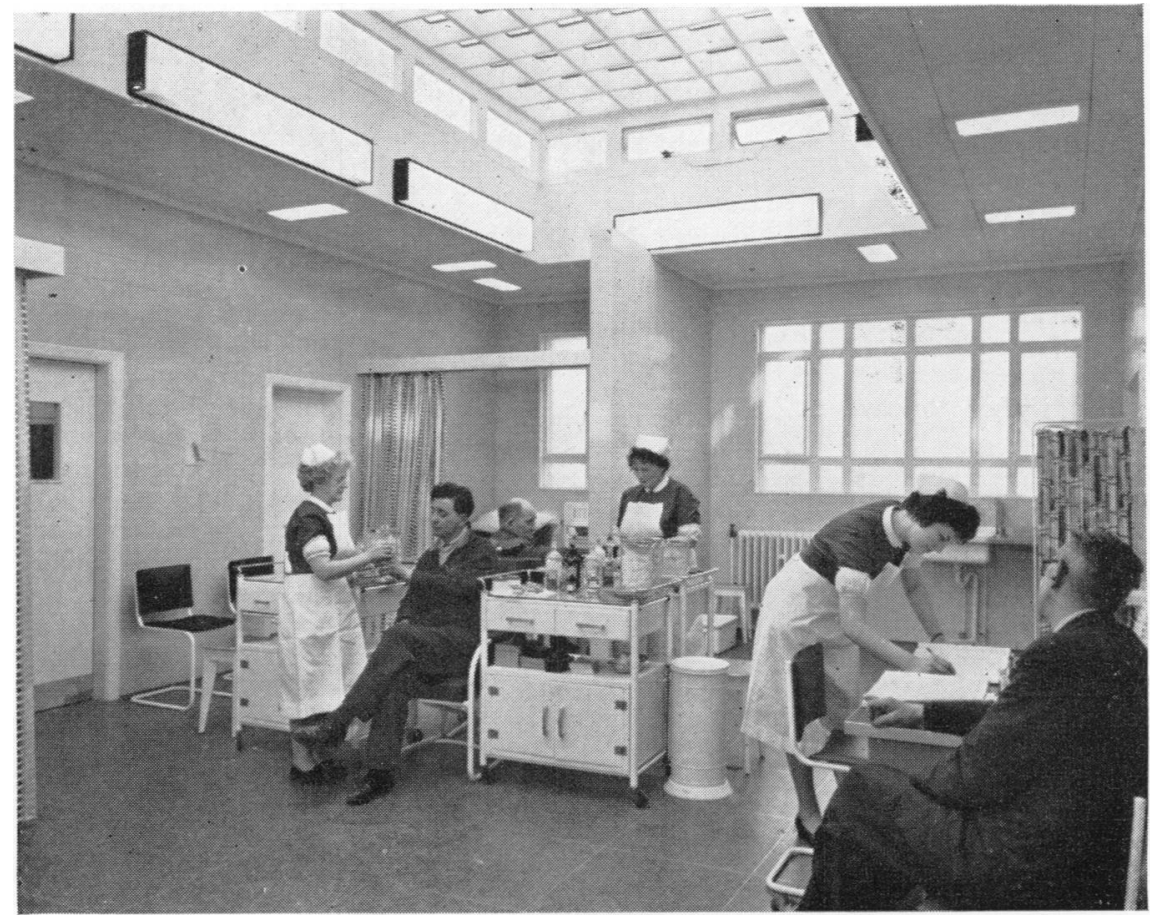

Fig. 4.-The main surgery has a "glasscrete" ceiling and walls of soft grey tiles. In the left background is the cubicle for minor surgical procedures.

A small sound-proof laboratory is provided for the use of the medical officers and as a base for the company's occupational hygiene unit, when engaged on investigations at Ebbw Vale.

The design artist responsible for the internal finishes has employed materials which can be maintained at a high standard of cleanliness. This has been achieved by using a limited number of paint colours, with wallpapers to give a texture effect, leaving curtains to introduce a note of colour where necessary. These are of a plastic material and are resistant to acid and chemicals. Black "granwood" flooring has been used except in the treatment rooms. The ceilings in the waiting area and treatment rooms are of acoustic tiles with recessed light fittings.

In the waiting hall area, one wall has been completely covered with plastic fabric with vertical aluminium cover strips to give a decorative effect emphasized by the use of glass pendant light fittings.

The built-in seating is covered with plastic material and provided with draught screens at each end in contrasting colours.

The dressings room (Fig. 4) has been tiled in soft grey, relief being given by the use of coloured curtains and contrasting coloured tiles in the adjoining spaces; the whole of this floor area is in dark terrazzo with brass inlay strips. Every window in the building is double glazed to reduce noise and dust to a minimum.

The staff of the medical department at Ebbw Vale consists of three doctors, a sister-in-charge, 22 nurses, eight rescue men, two hygiene supervisors and a physiotherapist. The three doctors also cover the Company's works at Panteg, Pontymister, and Abercarn, where there are permanent surgeries, all staffed by nurses.

The aim of the medical service is both preventive and therapeutic.

The preventive programme includes the selective placing of personnel, medical supervision aimed to maintain the highest possible standard of health, control of the environment, making use of an occupational hygiene team, and public health control in co-operation with local Medical Officers of Health.

The therapeutic programme, organized in co-operation with local general practitioners and hospitals, provides treatment for occupational injuries and illnesses and, in certain cases, for non-occupational conditions. Depending on local needs, special facilities such as resuscitation, radiology, physiotherapy, and rehabilitation are provided. 